\title{
Nanoscale Mechanical Evaluation of Electrochemically Generated Tribolayer on CoCrMo Alloy for Hip Joint Application
}

\author{
Gina Quiram ${ }^{1}$ - Izabelle M. Gindri ${ }^{1} \cdot$ S. Kerwell ${ }^{2} \cdot$ K. Shull $^{3} \cdot$ Mathew T. Mathew $^{2}$. \\ Danieli C. Rodrigues ${ }^{1}$
}

Received: 8 December 2015/Revised: 13 April 2016/Accepted: 19 April 2016/Published online: 2 May 2016

(C) Springer International Publishing Switzerland 2016

\begin{abstract}
Cobalt chromium molybdenum alloy (CoCrMo) is widely employed in the orthopedic device industry due to a combination of properties that include low wear, high mechanical strength, and high corrosion resistance. However, when used as the bearing component of total hip implants, this material can be susceptible to wear and corrosion, which can be triggered or exacerbated by factors such as changing $\mathrm{pH}$, biological fluids and cell interactions, particle release, and friction. The physiological fluid, which is composed of electrolytes, proteins, and other organic species, plays a critical role in the tribological behavior of CoCrMo alloy. The aim of this work is to generate a proteinaceous layer electrochemically and carry out nanoscale mechanical and surface evaluation of CoCrMo to understand the feasibility of a pre-treatment on this material. The treatments consisted of electrolytes, with different protein concentrations, and pre-selected transpassive potentials at $+0.6,+0.7$ and $+0.8 \mathrm{~V}$ and a passive potential of $-0.4 \mathrm{~V}$. These observations will help in determining the electrolyte concentration and potential combination that would yield the most protective film layer. The results demonstrated that all the positive transpassive potentials and electrolyte combinations led to surface degradation processes causing more material removal as seen by the formation of localized corrosion at carbide and grain boundaries. Only the
\end{abstract}

Danieli C. Rodrigues

danieli@utdallas.edu

1 Department of Bioengineering, University of Texas at Dallas, Richardson, TX 75080, USA

2 Section of Tribology, Department of Orthopedic Surgery, Rush University Medical Center, Chicago, IL 60612, USA

3 Department of Material Science and Engineering, Northwestern University, Evanston, IL 60201, USA negative potential of $-0.4 \mathrm{~V}$, used by itself as a pretreatment and in combination with an electrolyte with $30 \mathrm{~g} /$ $\mathrm{L}$ of bovine calf serum (BCS), demonstrated more homogeneous oxide layer and proteinaceous layer distribution respectively.

Keywords Cobalt chromium molybdenum - Tribological behavior - Transpassive potentials - Coefficients of friction - Electrochemical and mechanical degradation . Third-body particle wear

\section{Introduction}

Among the several metals commercially used in the design of articulation components for hip arthroplasty, CoCrMo is one of the most employed. This material is particularly used in the design of components that undergo friction and motion due to their high wear and corrosion resistance. However, the articulating interfaces of hip implants designed with CoCrMo may undergo a process called tribocorrosion under specific conditions. During this process, the components of the implant experience a surface degradation phenomenon (wear, cracking, corrosion, etc.) subjected to the combined action of mechanical loading (friction, abrasion, erosion, etc.) and environmental corrosion (chemical and/or electrochemical interactions) [3, 24, 34].

Retrieval studies demonstrated that the presence of a proteinaceous layer (also called tribolayer, mixture of metal ions/debris and denatured protein) [26, 49] on implant surfaces creates superior tribological and electrochemical properties $[29,30]$. A previous study also showed that a similar type of layer could be generated on CoCrMo alloy electrochemically at the transpassive potential $(+0.6$ 
to $+0.8 \mathrm{~V}$ ); [28]. However, there is lack of information regarding the mechanical stability of such layers.

The clinical significance of the electrochemical interactions of CoCrMo surfaces with proteins and body fluids in vivo has been for several years the focus of numerous investigations [16-18, 22, 33, 38]. The complex in vivo environment with electrochemical and mechanical degradation mechanisms not only impacts the longevity of a device but also the safety of patients, since wear of these alloys can lead to hypersensitivity and pseudotumors from ion and particle release to surrounding tissues $[1,5,7,15$, 45]. Several studies of well-functioning MoM (metal-onmetal) hip prostheses, in which the predominant mechanism of degradation was minor surface fatigue, tribocorrosion, and chemical reactions, have been reported [2, 10, 49, 50]. Moreover, the presence of corrosion and debris in these situations over a long period of time can adversely affect surrounding tissues and later clinical failure of an implant such as aseptic loosening and osteolysis [12, 42].

The composition of the spontaneous passive layer formed on CoCrMo consist mostly of hydrated $\mathrm{Cr}$ - and $\mathrm{Co}$ (III) oxides $\left(\mathrm{Cr}_{2} \mathrm{O}_{3}, \mathrm{Cr}(\mathrm{OH})_{3}, \mathrm{Co}(\mathrm{OH})_{2}\right)$, with very low dissolution of Mo [16, 33]. The ratio of $\mathrm{Co}$ to $\mathrm{Cr}$ and the level of hydration of the passive layer changes and depends on potentiostatic conditions [32]. The passive layer range is from $-0.3 \mathrm{~V}$ to approximately $+0.5 \mathrm{~V}$ when transpassive oxidation begins. At more positive potentials, the current density increases in the transpassive range and formation of $\mathrm{Cr}(\mathrm{VI})$ species is observed and merge in the layer. Film breakdown begins at around $+0.3 \mathrm{~V}$ and is completely broken down by $0.5 \mathrm{~V}$ [13]. It has been reported that after anodic oxidation of CoCrMo alloys $\mathrm{Cr}$ (III) tends to be enriched, $\mathrm{Cr}(\mathrm{VI})$ oxide is formed, $\mathrm{Co}(\mathrm{II})$ depleted in the oxide, and Mo-oxide (VI) formed. These observations were obtained from experiments performed in simulated physiological solutions (Hanks simulated physiological solution and synovial fluid). Furthermore, organic molecules (proteins) and salts present in physiological solutions accelerate the corrosion process $[37,46,48]$. Thus, when CoCrMo is exposed to the physiological environment, its passive film changes with time through the adsorption of ions present in the electrolyte solution. Even though there is an increase in the thickness of the oxide film, once the transpassive voltage has been reached, the dissolution rate of the alloy also increases [16]. Another factor that can affect CoCrMo in the long term is the third-body particle wear. This process involves two articulating surfaces as well as an abrasive third-body particle that can aggravate the damage of the protective oxide layer [43].

Hip joint implant is in contact with synovial fluid and released ions from the alloy can interact with proteins and form proteinaceous films. The serum proteins that have been modified or degraded by the presence of metal ions and particle release can influence the kinetics and means of tribocorrosion and the formation of carbonaceous matter [4, 30, 51]. Therefore, it is of great clinical significance to identify how proteins from synovial fluid arrange and interact with the surface of metal implants.

This study aims to understand corrosion processes that may take place during the formation of a simulated tribolayer on CoCrMo alloy. This is accomplished by characterizing the surface roughness and coefficients of friction (COF) at nanoscale levels using AFM techniques. SEM/ EDS were also performed to characterize the composition and structures on the surface of the alloy for different treatments. This study aims to elucidate the role that synovial fluid has on CoCrMo when exposed to different transpassive potentials. We attempted to reproduce a proteinaceous layer using transpassive potentials of +0.6 , +0.7 , and $+0.8 \mathrm{~V}$. In addition to these, $-0.4 \mathrm{~V}$ was chosen, which is the potentials of passive layers on the CoCrMo alloy. Bovine calf serum (BCS) was used as alternative medium for synovial fluid. Three different electrolytes with varying protein concentrations $(0,15$, and $30 \mathrm{~g} / \mathrm{L}$ BCS) were used. Studying the morphology of the passive film and how protein deposition takes place under different anodic and cathodic potential treatments can elucidate the feasibility of using this carbonaceous layer as a pre-treatment method for hip implant.

\section{Experimental Section}

\subsection{Samples}

In this study, seven CoCrMo samples with electrochemically generated films $(12 \times 3 \mathrm{~mm})$ were used. The composition of the disk samples is shown in Table 1 .

The electrolyte used was bovine calf serum (BCS), which was diluted to a few protein concentrations using a buffered basic solution. $10 \mathrm{~mL}$ of surrounding electrolyte was used and electrochemical tests were conducted at $37^{\circ} \mathrm{C}$. Table 2 describes the composition of the electrolyte formulated.

The composition of the protein (serum-based solution) is albumin, gamma globulin, transferrin, and fibrinogen, with albumin as the major constituent.

Each of the voltages and their respective electrolyte protein concentrations used are listed in Table 3.

\subsection{Methodology}

\subsubsection{Electrochemical Treatment of CoCrMo Samples}

CoCrMo alloy samples electrochemically treated were used for the AFM study. Electrochemical treatment was 
Table 1 Wrought high carbon (HC) CoCrMo alloy chemical composition (wt\%)

\begin{tabular}{lllllll}
\hline Carbon & Cobalt & Chromium & Molybdenum & Silicon & Aluminum & Manganese \\
\hline 0.03 & 64.9 & 27.5 & 5.7 & 0.38 & $<0.02$ & 0.60 \\
\hline
\end{tabular}

(HC) CoCrMo alloy ASTM ${ }^{\mathrm{TM}}$ F75 supplied by Alvac Incorporated

Table 2 Composition of electrolyte (BCS)

\begin{tabular}{llll}
\hline \multicolumn{4}{l}{ Composition of Bovine calf serum (BCS) electrolyte } \\
\hline $\mathrm{NaCl}(\mathrm{g} / \mathrm{L})$ & EDTA $(\mathrm{g} / \mathrm{L})$ & Tris $(\mathrm{g} / \mathrm{L})$ & Protein $(\mathrm{g} / \mathrm{L})$ \\
\hline 9 & 0.2 & 27 & 30 \\
\hline
\end{tabular}

Table 3 Summary of CoCrMo alloy samples prepared for the study

\begin{tabular}{lll}
\hline $\begin{array}{l}\text { Sample } \\
\text { A1 }\end{array}$ & $\begin{array}{l}\text { Voltage }(\mathrm{V}) \\
\text { Untreated }\end{array}$ & $\begin{array}{l}\text { Electrolyte protein } \\
\text { concentration }(\mathrm{BCS} \text { g/L) }\end{array}$ \\
\hline B1 & +0.7 & 0 \\
B2 & +0.7 & 15 \\
B3 & +0.7 & 30 \\
C1 & +0.8 & 30 \\
D1 & +0.6 & 30 \\
E1 & -0.4 & 0 \\
E2 & -0.4 & 30 \\
\hline
\end{tabular}

done on 21 CoCrMo alloy disks $(12 \mathrm{~mm} \times 3 \mathrm{~mm})$ that were supplied by Alvac Incorporated, using $n=3$ for each of the treatment conditions (potential treatment and electrolyte). Wrought high carbon (HC) CoCrMo alloy was prepared using ASTM standards [ASTM F75 1998], in which the polishing procedure consisted of steps between 250 and 800 grit paper and 6 and $1 \mu \mathrm{m}$ polishing cloths for CoCrMo surfaces (average roughness, $R_{\mathrm{a}}<15 \mathrm{~nm}$ ).

A custom-built 3-electrode electrochemical corrosion cell was used for all electrochemical testing. In the treatment process, the working electrode (WE) consisted of CoCrMo disks (exposed area of $0.38 \mathrm{~cm}^{2}$ ), a saturated calomel electrode (SCE) was used as the reference electrode (RE), and a graphite rod as the counter electrode (CE).

The first parameter was the specific potential treatment. The potential was selected based on the potentiodynamic curves of CoCrMo in BCS, as shown in Fig. 1. The selected potentials were from either the passive potential $(-0.4 \mathrm{~V}$ vs $\mathrm{SCE})$ or the transpassive potential region $(+0.6,+0.7$, and $+0.8 \mathrm{~V}$ vs SCE) [28]. The second parameter was the protein concentration of the surrounding electrolyte within the electrochemical cell. Concentrations included: 0,15 , and $30 \mathrm{~g} / \mathrm{L}$ of protein. Specifically, for this study, the transpassive potentials used with their respective protein content of BCS were as follows: $+0.6 \mathrm{~V}(30 \mathrm{~g} / \mathrm{L})$, $+0.7 \mathrm{~V}(0,15$, and $30 \mathrm{~g} / \mathrm{L}),+0.8 \mathrm{~V}(30 \mathrm{~g} / \mathrm{L})$, and $-0.4 \mathrm{~V}$

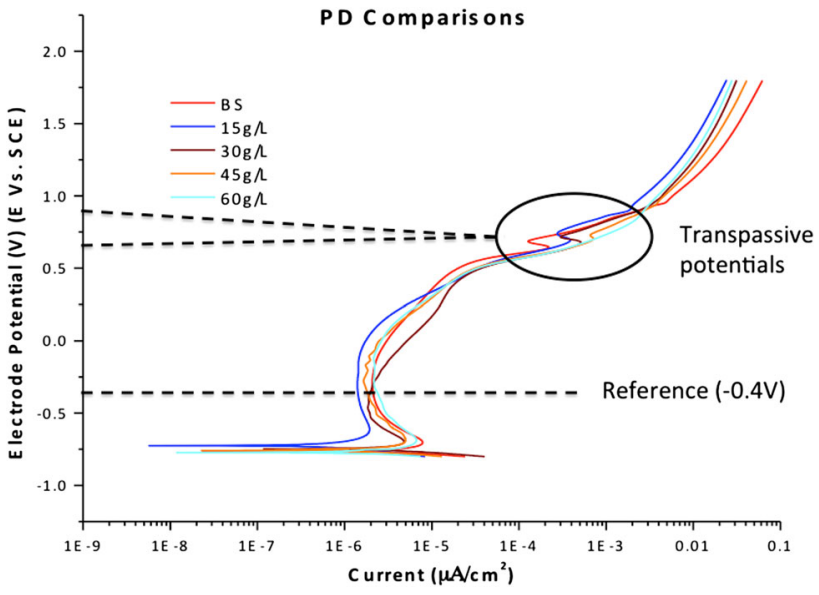

Fig. 1 Potentiodynamic test results of CoCrMo in various electrolyte concentrations. The curve shows the transpassive region (from +0.6 to $+0.8 \mathrm{~V}$ ), where the current is decreased, indicating possible secondary film formation

( 0 and $30 \mathrm{~g} / \mathrm{L}$ ). The highest electrolyte concentration of BCS protein content was $30 \mathrm{~g} / \mathrm{L}$, which is the concentration of protein found in vivo during inflammatory conditions.

The electrochemical treatment protocol was performed following the steps: (1) open-circuit potential to determine all wire connections were accurate; (2) potentiostatic measurements were conducted at $-0.9 \mathrm{~V}$ to ensure the alloy surface was properly cleaned (cleaning phase); (3) opencircuit potential to monitor the potential after cleaning; (4) electrochemical impedance spectroscopy (EIS) to determine the surface characteristics of the alloy (outputs are Nyquist and Bode plots); (5) potentiostatic polarization at $+0.6 \mathrm{~V}(30 \mathrm{~g} / \mathrm{L}),+0.7 \mathrm{~V}(0,15$, and $30 \mathrm{~g} / \mathrm{L}),+0.8 \mathrm{~V}$ $(30 \mathrm{~g} / \mathrm{L}),-0.4 \mathrm{~V}(0$ and $30 \mathrm{~g} / \mathrm{L})$; (6) open-circuit potential in order to determine the stabilizing potential after the treatment step was performed and also to compare to the potential obtained in Step 3. The electrochemical cell was maintained at $37{ }^{\circ} \mathrm{C}$ for one hour, during all electrochemical treatments.

\subsubsection{Nano-mechanical and Morphological Analysis of CoCrMo Samples}

After the electrochemical treatment, high-resolution 3D size and shape characterization mapping and roughness data of CoCrMo samples were obtained using an atomic force microscope (AFM Bioscope Catalyst ${ }^{\mathrm{TM}}$, Bruker ${ }^{\mathrm{TM}}$, 
CA). For each treatment, two different areas were analyzed, the center and edges, and from each area, two sections were evaluated $(n=2)$. These experiments were executed on PeakForce tapping ${ }^{\mathrm{TM}}$ mode with the quantitative nanomechanics method $\left(\mathrm{QNM}^{\mathrm{TM}}\right)$ in air for material property mapping, which besides morphological features enables quantitative measurement of nanoscale material properties. Roughness average " $\mathrm{R}_{\mathrm{a}}$ " of asperities on CoCrMo samples was evaluated over areas ranging from 5 to $15 \mu \mathrm{m}$. This was the technique of choice because it dramatically exceeds the capabilities of any other technique. It also allowed for higher resolution topography images, keeping indentations small, and eliminating lateral forces, which preserved both the tip and the sample. Offline analysis functions calculated statistics of the mechanical properties of different areas through the data to show the spatial allocation of properties. Data acquisition and image processing were obtained using NanoScope ${ }^{\circledR}$ software.

\subsubsection{Nanoscale Evaluation of Coefficient of Friction (COF) of CoCrMo Samples}

The coefficient of friction (COF), at the nanoscale level, of CoCrMo samples was obtained using AFM in contact mode imaging with lateral force microscopy (LFM). The AFM probe was in contact with the surface to be scanned and the friction between the sample and the tip resulted in a detected voltage [14, 19, 25]. From this voltage, frictional properties of the CoCrMo alloy could be calculated [44]. The scanning was done perpendicular to the long axis of the cantilever using a sharp nitride lever (SNL-10). A probe made out of silicon nitride with a nominal spring constant $(k=0.35 \mathrm{~N} / \mathrm{m})$ and a nominal frequency $(f=65 \mathrm{kHz})$. The friction voltage signal (half of the difference between trace and retrace signals) was converted to units of force and respective calibration using the methodology proposed by Kulik and Lekka [23]. Coefficients of friction were calculated over scanned areas of $1 \mu \mathrm{m}$ on different locations $(n=2)$. The data were analyzed using Bearing Analysis (NanoScope ${ }^{\circledR}$ Software function used to perform statistical analysis of the data). Due to the high wear rate of the tips while in contact mode, which was necessary to perform friction scanning, smaller scan areas were used for frictional experiments. Some factors that accelerated the wear of the tips in our experiment included adhesion forces from the BCS (Bovine Calf Serum), degree of corrosion present on the surface, and sample inhomogeneity.

\subsubsection{Energy-dispersive X-ray Analysis}

Energy-dispersive X-ray spectrometry (EDS) analysis was used to evaluate the elemental compositions of CoCrMo alloy surfaces and to confirm the presence of organic material and/or corrosion effects following different electrochemical treatments. Proteins primarily consist of carbon, nitrogen, hydrogen, and oxygen. Nitrogen compounds can be detected using EDS with a peak that is typically observed near $0.39 \mathrm{keV}$, which can be attributed to the presence of protein on the sample surfaces. An $\mathrm{EVO}^{\mathrm{TM}}$ SEM LS15 (Zeiss ${ }^{\text {TM }}$, Germany) equipped with an EDS (IXRF systems, Inc. Austin, TX) and built-in software was used to capture EDS spectra of the different CoCrMo alloy samples' surface after each electrochemical treatment between 0 and $10 \mathrm{keV}$.

\section{Results}

Topology characterization of different samples, treated either with anodic oxidation or cathodic reduction, was carried out to investigate the distribution and features of the tribolayer we attempted to simulate. The surface of these pre-treated disks was compared with the surface of a CoCrMo control sample (not subjected to electrochemical treatment). The treatments can be divided into two different categories: (a) disks pre-treated with anodic oxidations (transpassive potentials: $+0.6,+0.7$, and $+0.8 \mathrm{~V}$ vs SCE) with different electrolyte concentrations $(0,15$, and $30 \mathrm{~g} / \mathrm{L}$ of BCS) and (b) disks pre-treated at passive potential of $-0.4 \mathrm{~V}$ versus SCE in the presence of electrolyte solutions of $0 \mathrm{~g} / \mathrm{L} \mathrm{BCS}$ and $30 \mathrm{~g} / \mathrm{L} \mathrm{BCS}$. This was done in order to compare the differences among tribolayer morphologies with passivation potentials and the start of depassivationtranspassive states. To better evaluate effects of the different treatments, the results are presented in two sections: (a) surface morphology and roughness and (b) coefficients of friction (COF). Each characterization provided different corrosion features that depended on protein deposits formed on the substrate from each type of treatment.

\subsection{Surface Morphology and Roughness}

The roughness was compared among all the samples that were treated with anodic and passive potentials (Fig. 2): B1 $(+0.7 \mathrm{~V}, 0 \mathrm{~g} / \mathrm{L}$ BCS $)$, B2 (+0.7 V, $15 \mathrm{~g} / \mathrm{L}$ BCS $),$ B3 $(+0.7 \mathrm{~V}, 30 \mathrm{~g} / \mathrm{L} \mathrm{BCS}), \mathrm{C} 1(+0.8 \mathrm{~V}, 30 \mathrm{~g} / \mathrm{L} \mathrm{BCS}), \mathrm{D} 1$ $(+0.6 \mathrm{~V}, 30 \mathrm{~g} / \mathrm{L} \mathrm{BCS}), \mathrm{E} 1(-0.4 \mathrm{~V}, 0 \mathrm{~g} / \mathrm{L} \mathrm{BCS})$, and E2 $(-0.4 \mathrm{~V}, 30 \mathrm{~g} / \mathrm{L} \mathrm{BCS})$. From the results, it was not possible to establish a clear pattern primarily because of the great variability and inhomogeneity across samples. This variability is observed in detail on the individual topographic images to follow for the different samples evaluated.

The respective calculated roughness $\left(R_{\mathrm{a}}\right)$ and the average maximum $\left(R_{\max }\right)$, which is the vertical distance between the highest and lowest data points on the image 


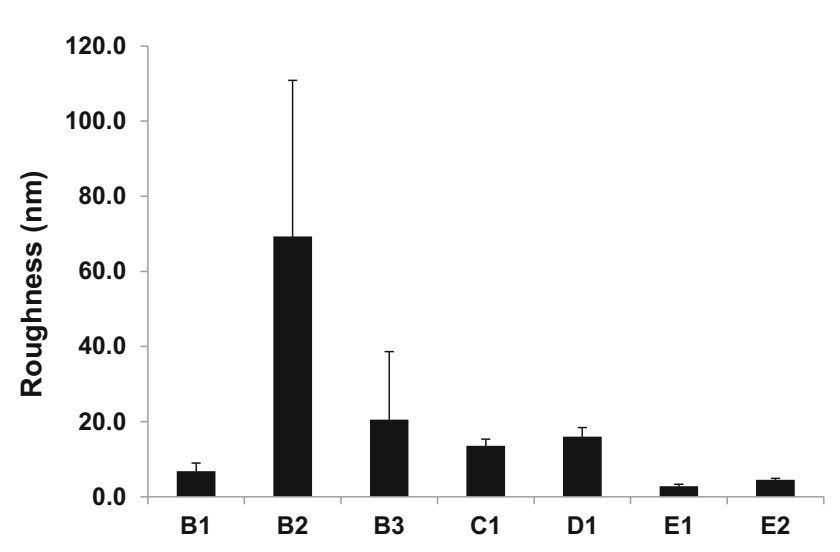

Fig. 2 Surface roughness obtained by AFM. Scans and values were obtained from the central area in each sample. Samples: B1 $(+0.7 \mathrm{~V}$, $0 \mathrm{~g} / \mathrm{L} \mathrm{BCS}), \mathrm{B} 2(+0.7 \mathrm{~V}, 15 \mathrm{~g} / \mathrm{L} \mathrm{BCS}), \mathrm{B} 3(+0.7 \mathrm{~V}, 30 \mathrm{~g} / \mathrm{L} \mathrm{BCS})$, C1 (+0.8 V, $30 \mathrm{~g} / \mathrm{L} \mathrm{BCS})$, D1 (+0.6 V, $30 \mathrm{~g} / \mathrm{L} \mathrm{BCS})$, E1 (-0.4 V, $0 \mathrm{~g} / \mathrm{L} \mathrm{BCS})$, and E2 (-0.4 V, $30 \mathrm{~g} / \mathrm{L} \mathrm{BCS})$

following the plane-fit for each sample, are tabulated in Table 4, for each sample with their respective COF.

(a) Sample $B 1(+0.7 \mathrm{~V}, 0 \mathrm{~g} / \mathrm{L} \mathrm{BCS})$ This high voltage applied caused aggressive oxidation on the surface of the CoCrMo disk as shown in the features of Fig. 3. The morphological maps were obtained by scanning areas $(n=2)$ of $5.5 \mu \mathrm{m}$ in Fig. $3 \mathrm{a}, \mathrm{b}$, which are the 2D and 3D images. To generate the images shown in Fig. 3c, d, the scanning area was $15 \mu \mathrm{m}$ in 2D and 3D. For sample B1, the depths of the basins ranged from 30 to $550 \mathrm{~nm}$ and their diameters ranged from $100 \mathrm{~nm}$ to $3.95 \mu \mathrm{m}$.

(b) Sample B2 $(+0.7 \mathrm{~V}, 15 \mathrm{~g} / \mathrm{L} \mathrm{BCS})$ Using $15 \mathrm{~g} / \mathrm{L}$ of BCS as the electrolyte resulted in inhomogeneous protein deposition with localized corrosion features around carbide and grain boundaries. There were regions with excessive buildup of protein concentrated in particular areas, especially around the corroded zones (Fig. 4). This treatment produced localized corrosion and grooves or basins of mixed carbides and carbonaceous material due to the presence of proteins in the BCS. The roughness for this sample (B2) was $69.3 \mathrm{~nm}$.

The diameters of the basins ranged from $783.72 \mathrm{~nm}$ to $2.03 \mu \mathrm{m}$. The protein agglomerates size ranged from 1 to $7.5 \mathrm{um}$ in diameter with heights from 25 to $100 \mathrm{~nm}$.

(c) Sample $B 3(+0.7 \mathrm{~V}, 30 \mathrm{~g} / \mathrm{L}$ BCS $)$ From Fig. 5, protein deposition was observed with similar distributions on the center and border sections, displaying some slight depressions. The surface morphology was similar to the one observed for sample B2. The roughness for this sample (B3) was $20.5 \mathrm{~nm}$, which is more than half of the one observed for sample B2 $(+0.7 \mathrm{~V}, 15 \mathrm{~g} / \mathrm{L} \mathrm{BCS})$. The only difference in treatments between samples B2 and B3 was the protein concentration used in the electrolyte. From the roughness profiles, it was observed that B3 got denser film deposition than B2. Basins were observed and their size reached up to $3.76 \mu \mathrm{m}$ in diameter (Fig. 4b, f). The protein agglomerates for sample B3 increased by a factor of almost 3 when compared with sample B2 with sizes ranging from $710 \mathrm{~nm}$ to $2.75 \mu \mathrm{m}$ in diameter.

(d) Samples $C 1(+0.8 \mathrm{~V}, 30 \mathrm{~g} / \mathrm{L} \mathrm{BCS})$ and $\mathrm{Dl}(+0.6 \mathrm{~V}$, $30 \mathrm{~g} / \mathrm{L} \mathrm{BCS}$ ) These two samples were treated with different voltages but with the same electrolyte concentration $(30 \mathrm{~g} / \mathrm{L}$ BCS). The samples displayed similar patterns with a few distinctive features. Sample C1 was treated with a voltage of $+0.8 \mathrm{~V}$ (Fig. 6a, b, e, and f). The protein was densely packed on the surface of this sample resulting in a roughness of $13.6 \mathrm{~nm}$. Most of the surface was covered with protein in a particularly inhomogeneous manner with heights varying between $40 \mathrm{~nm}$ and $1.1 \mu \mathrm{m}$. The diameter of the agglomerates ranged from $540 \mathrm{~nm}$ to $8.64 \mu \mathrm{m}$. There were also a few basins with sizes up to $6.62 \mu \mathrm{m}$ in diameter and $254 \mathrm{~nm}$ in depth. Even
Table 4 Electrochemical treatment conditions used and their respective roughness values

\begin{tabular}{|c|c|c|c|c|c|}
\hline Sample & Voltage & Protein concentration & $R_{\mathrm{a}}^{\mathrm{a}}(\mathrm{nm})$ & $R_{\max }^{\mathrm{b}}(\mathrm{nm})$ & $\operatorname{COF}^{\mathrm{c}}(\mu)$ \\
\hline B1 & +0.7 & 0 & 6.8 & 14.4 & 0.072 \\
\hline B2 & +0.7 & 15 & 69.3 & 117.0 & 0.011 \\
\hline B3 & +0.7 & 30 & 20.5 & 46.9 & 0.135 \\
\hline C1 & +0.8 & 30 & 13.6 & 17.9 & 0.005 \\
\hline D1 & +0.6 & 30 & 16.0 & 22.6 & 0.008 \\
\hline E1 & -0.4 & 0 & 2.8 & 5.88 & 0.004 \\
\hline E2 & -0.4 & 30 & 4.5 & 6.99 & 0.007 \\
\hline
\end{tabular}



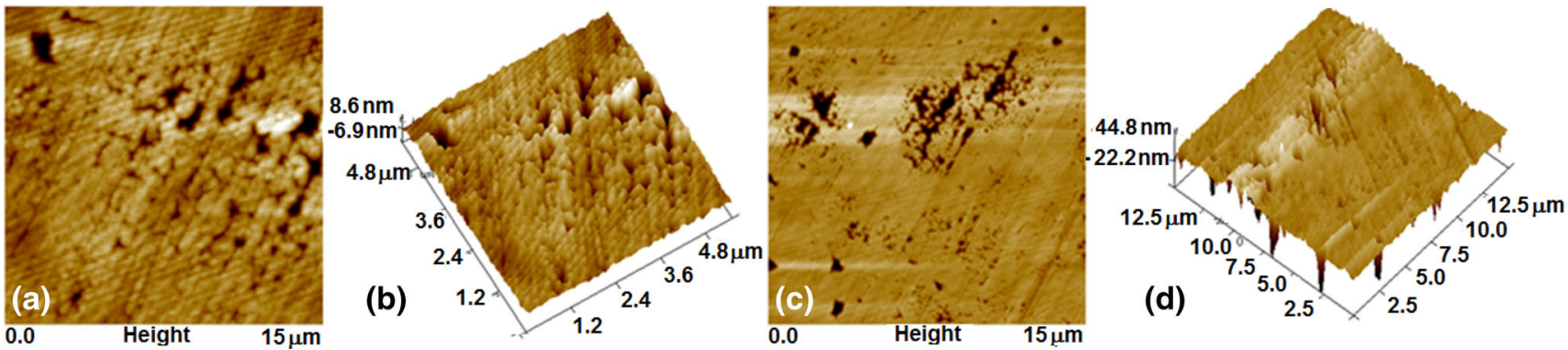

Fig. 3 Atomic force microscopy (AFM) scanning images of CoCrMo-treated electrochemically with $+0.7 \mathrm{~V}$ and 0 g/L of BCS (sample B1). (a, b) Scanning area used $5.5 \mu \mathrm{m}$. (c, d) Scanning area used $15 \mu \mathrm{m}$
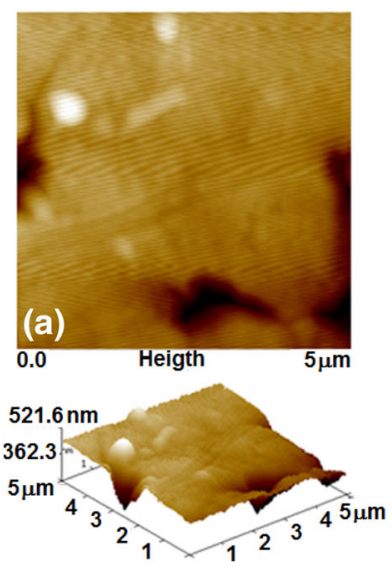

(e)

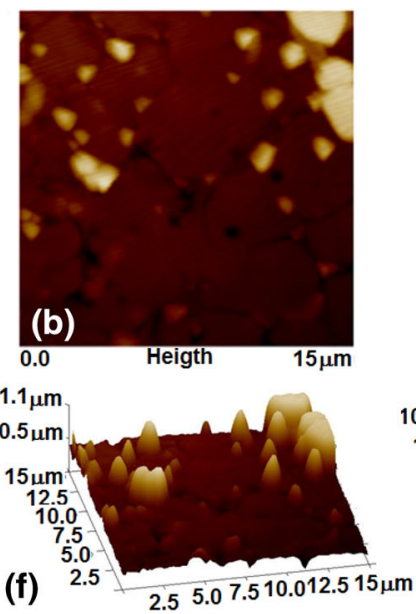

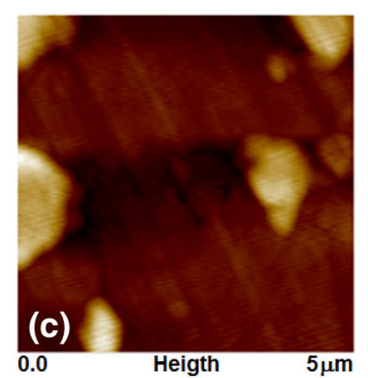

(g)

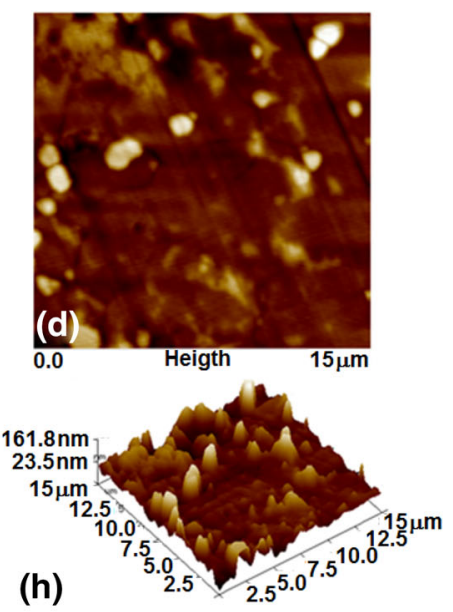

(h)

Fig. 4 Atomic force microscopy (AFM) 2D and 3D scanning images of CoCrMo-treated electrochemically with $+0.7 \mathrm{~V}$ and $15 \mathrm{~g} / \mathrm{L}$ of BCS (Sample B2). a, c, e, g Scanning area used $5.5 \mu \mathrm{m}$. b, d, f, h Scanning area used $15 \mu \mathrm{m}$
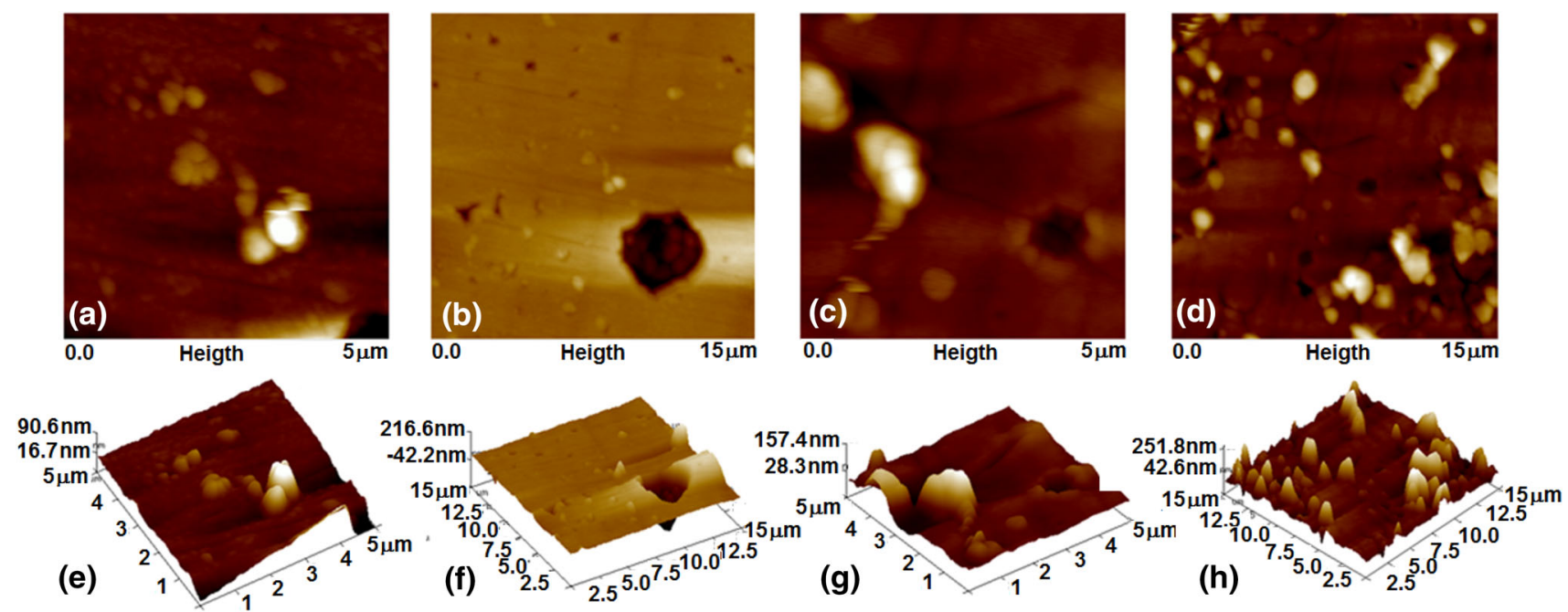

Fig. 5 Atomic force microscopy (AFM) 2D and 3D scanning images of CoCrMo alloy-treated electrochemically with $+0.7 \mathrm{~V}$ and $30 \mathrm{~g} / \mathrm{L}$ of BCS (Sample B3). a, c, e, g Scanning area used $5.5 \mu \mathrm{m}$. b, d, f, h Scanning area used $15 \mu \mathrm{m}$

though there were fewer basins most of them exhibited broad diameters and significant depths, when compared to the other transpassive potential treatments used for this study.
Sample D1 was treated electrochemically with a lower voltage of $+0.6 \mathrm{~V}$ and $30 \mathrm{~g} / \mathrm{L}$ BCS. Figure $6 \mathrm{c}$, $\mathrm{d}, \mathrm{g}$, and $\mathrm{h}$ displayed more patches of protein and basins wide-ranging in size and depth than sample 

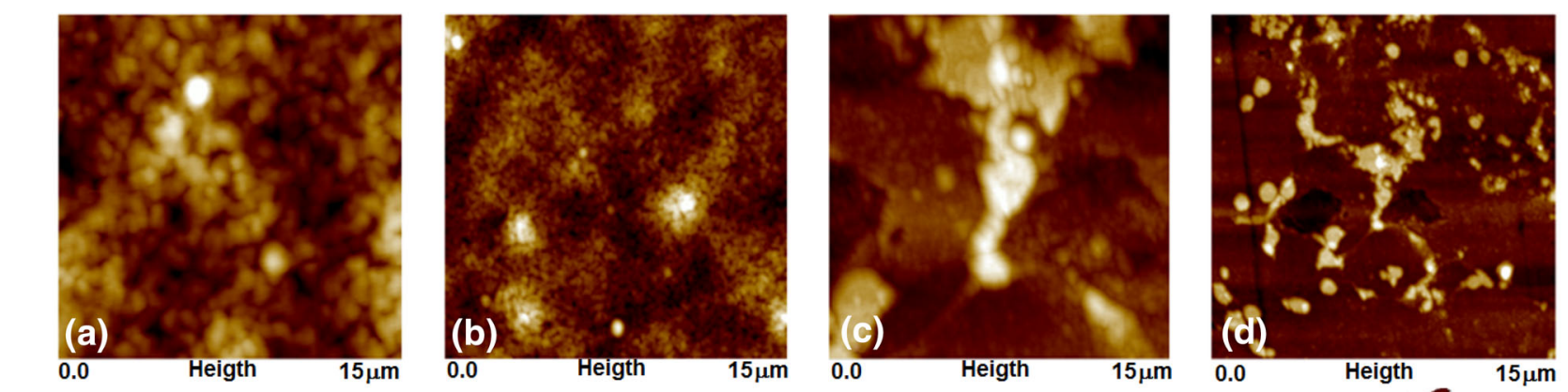

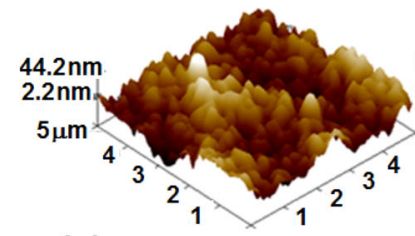

(e)

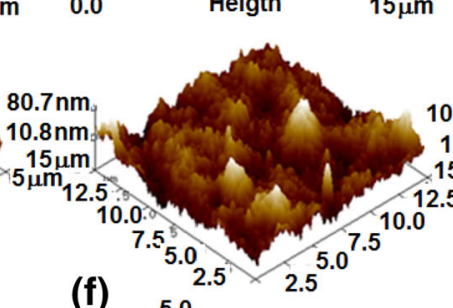

(f)

5.0

Fig. 6 Atomic force microscopy (AFM) 2D and 3D scanning images. $\mathbf{a}, \mathbf{b}, \mathbf{e}, \mathbf{f}$ correspond to sample C1-treated electrochemically with $+0.8 \mathrm{~V}, 30 \mathrm{~g} / \mathrm{L}$ BCS (Sample C-1), and $\mathbf{c}, \mathbf{d}, \mathbf{g}, \mathbf{h}$ correspond to

C1. The surface of sample D1 had protein agglomerates of up to $3.61 \mu \mathrm{m}$ in diameter and basins with dimensions of about $2.34 \mu \mathrm{m}$ in diameter and $60 \mathrm{~nm}$ in depth.

(e) Samples E1 (-0.4 V, O g/L BCS) and E2 (-0.4 V, $30 \mathrm{~g} / \mathrm{L} \mathrm{BCS}$ ) Sample E1 (Fig. 7a, b, e, and f) was subjected to a negative potential in the presence of an electrolyte devoid of any protein. The AFM topographical images showed an uniform oxide layer throughout the entire surface (edges and center of alloy). This sample did not display corrosion features only some polishing marks and artifacts from dust particles (white spots) were detected. The average roughness was $2.8 \mathrm{~nm}$.

Sample E2 (Fig. 7c, d, g, and h) was treated with the same voltage as sample E1 but in the presence of an electrolyte containing $30 \mathrm{~g} / \mathrm{L}$ of BCS. As seen from its $3 \mathrm{D}$ topographic mapping, there was a thin protein layer formation on the surface of the sample. The layer showed inhomogeneous spots not completely covering the surface. In Fig. 7c, d, there is visible scratching but no evidence of localized corrosion on the surface. The protein deposition was concentrated around the grain boundaries, carbide boundaries, and defects.

The protein layer formed in some areas created agglomerates with average height values of $8 \mathrm{~nm}$ and a maximum height of $18 \mathrm{~nm}$. Protein did not tend to agglomerate or deposit on areas that had defects or polishing marks as it happened on the samples treated with anodic potentials and electrolytes containing BCS. The roughness was about $4.52 \mathrm{~nm}$, which was slightly higher than the roughness obtained for sample E1 $(-0.4 \mathrm{~V}$ without protein in the electrolyte).

\subsection{Coefficient of Friction (COF)}

The relationship between electrochemical treatment and COF can be observed in Fig. 8.

(a) Anodic treatment samples $\mathrm{B} 1(+0.7 \mathrm{~V}, 0 \mathrm{~g} / \mathrm{L} \mathrm{BCS})$, B2 $(+0.7 \mathrm{~V}, 15 \mathrm{~g} / \mathrm{L}$ BCS $), B 3(+0.7 \mathrm{~V}, 30 \mathrm{~g} / \mathrm{L}$ BCS), C1 (+0.8 V, $30 \mathrm{~g} / \mathrm{L} \mathrm{BCS})$, and D1 $(+0.6 \mathrm{~V}$, $30 \mathrm{~g} / \mathrm{L}$ BCS).

Samples treated with anodic potentials $(+0.6 \mathrm{~V}$, $+0.7 \mathrm{~V},+0.8 \mathrm{~V})$ and in the presence of protein exhibited significant protein aggregation showed lower COF than the control A1 (no electrochemical treatment).

Sample B2 (15 g/L BCS) formed basins of highviscosity material leading to low $\mathrm{COF}$, acting as a lubricant in some areas. COFs ranged from $9.8 \times 10^{-3}$ to $1.22 \times 10^{-2}$ with a mean value of $1.1 \times 10^{-2}$. The average value for the $\mathrm{COF}$ in sample B3 was 0.135 . This value was higher than the one for $\mathrm{B} 2$, for which protein concentration was lower. For $\mathrm{C} 1$, the average $\mathrm{COF}$ was $4.8 \times 10^{-3}$ and values fluctuated between $4.54 \times 10^{-3}$ and $5 \times 10^{-3}$ among the different sections where COF was measured on this particular sample center and border, respectively. However, the $\mathrm{C} 1$ mean average was smaller than B3 and D1, which had equivalent electrolyte concentrations to $\mathrm{C} 1$ (30 g/L BCS), with 

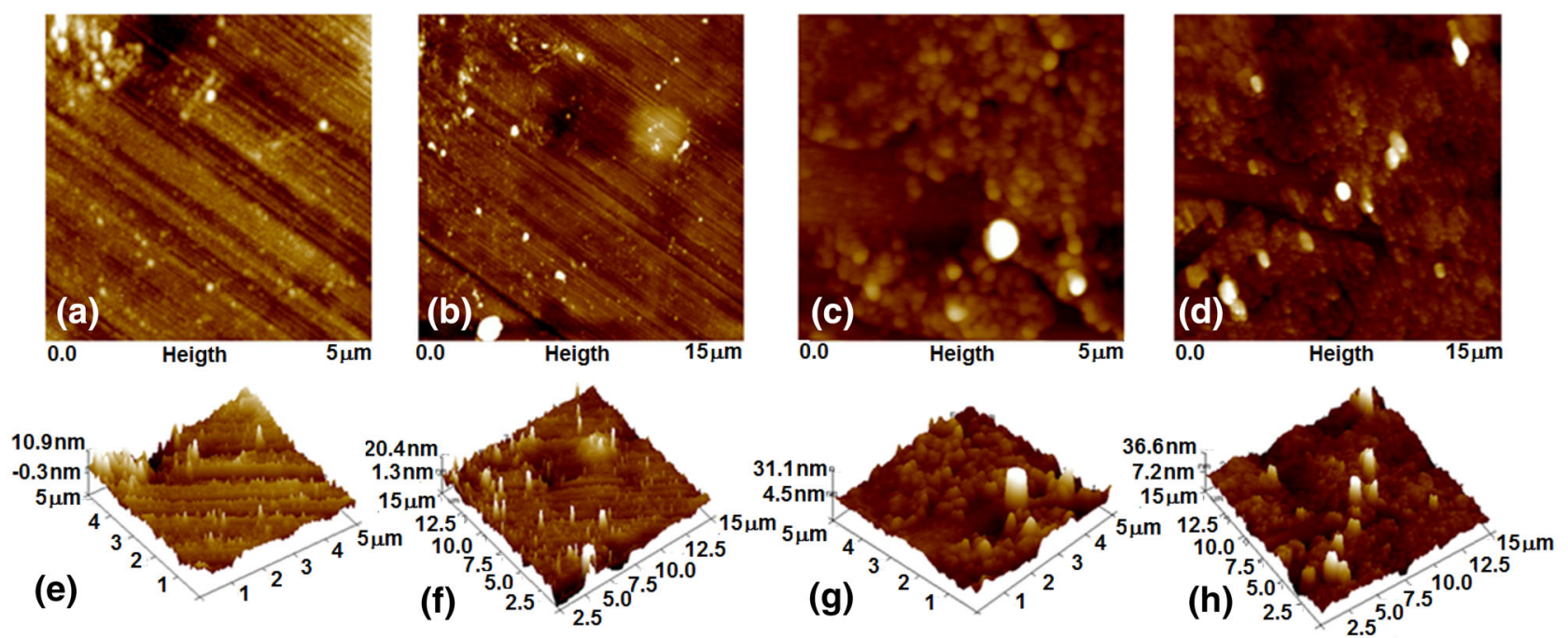
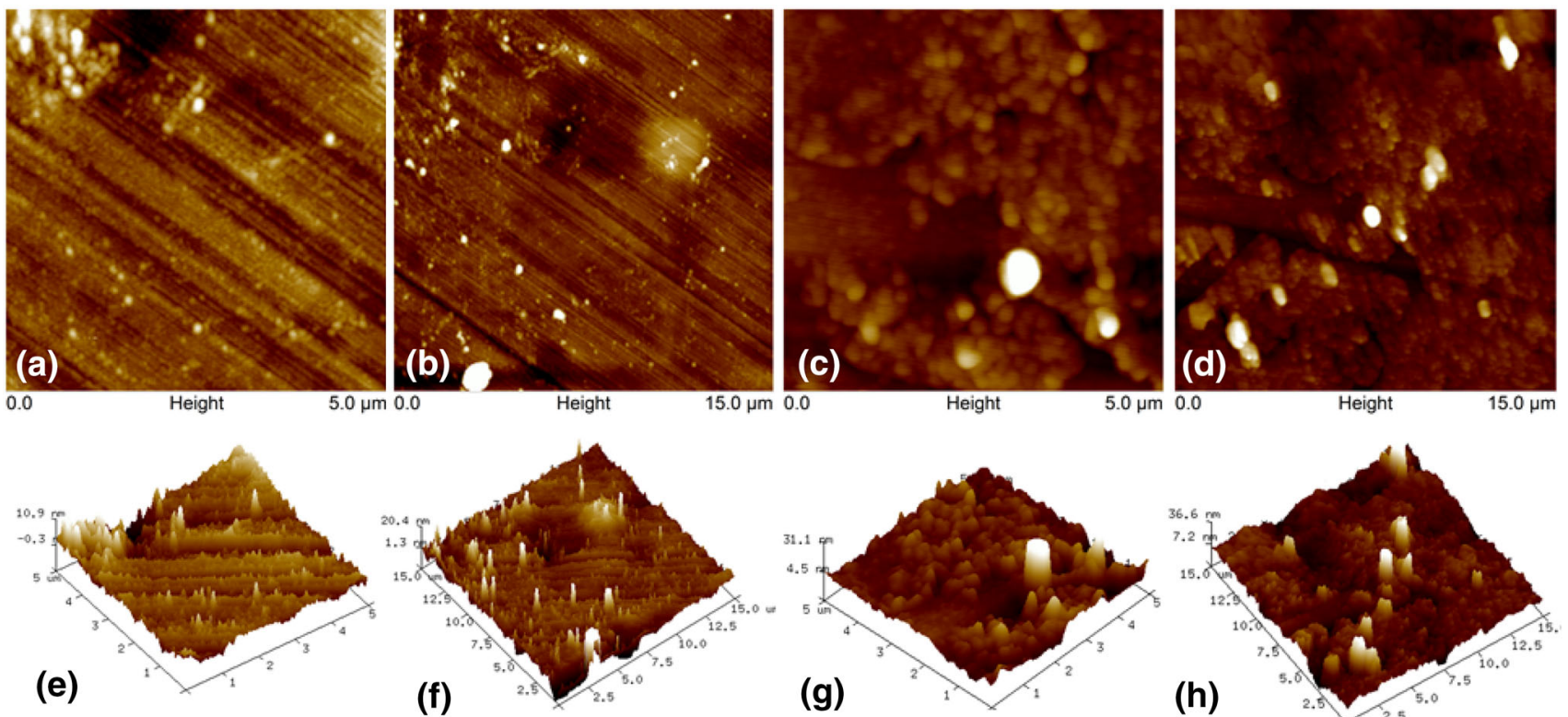

(f)

Fig. 7 Atomic force microscopy (AFM) 2D and 3D scanning images of CoCrMo sample-treated electrochemically with $\mathbf{a}, \mathbf{b}, \mathbf{e}, \mathbf{f}-0.4 \mathrm{~V}$, $0 \mathrm{~g} / \mathrm{L}$ BCS, and c, d, g, h sample-treated electrochemically with

$\mathrm{C} 1$ having the highest anodic potential of $+0.8 \mathrm{~V}$ used in this study. Sample D1-treated electrochemically at $+0.6 \mathrm{~V}, 30 \mathrm{~g} / \mathrm{L}$ BCS had an average COF of $7.82 \times 10^{-3}$

(b) Treated samples at Passive potentials E1 $(-0.4 \mathrm{~V}$, $0 \mathrm{~g} / \mathrm{L} \mathrm{BCS})$ and E2 $(-0.4 \mathrm{~V}, 30 \mathrm{~g} / \mathrm{L} \mathrm{BCS})$ : The passive potential of $-0.4 \mathrm{~V}$ in the presence of BCS developed in a much lower COF $\left(6.61 \times 10^{-3}\right)$ in comparison to the control A1 $\left(2.85 \times 10^{-2}\right)$ with values ranging from $8 \times 10^{-3}$ to $5.2 \times 10^{-3}$. Sample E1 treated with a negative potential of $-0.4 \mathrm{~V}$ and with no protein present in the electrolyte

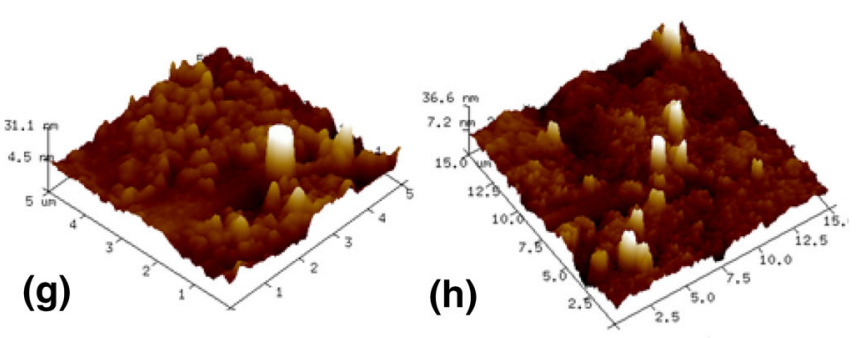

$-0.4 \mathrm{~V}, 30 \mathrm{~g} / \mathrm{L}$ BCS. a, c, e, $\mathbf{g}$ Scanning area used $5.5 \mu \mathrm{m} . \mathbf{b}, \mathbf{d}, \mathbf{f}$, h Scanning area used $15 \mu \mathrm{m}$

produced a more homogeneous friction coefficient than any of the other treatments investigated, which was also lower than the COF of A1. The average $\mathrm{COF}$ for E1 was $4.3 \times 10^{-3}$ and it was mostly constant throughout all the surface (border and center).

\subsection{EDS Analysis}

Although minor alloying elements have at most $1 \%$ by weight in the alloy, for simplicity only cobalt, chromium, 


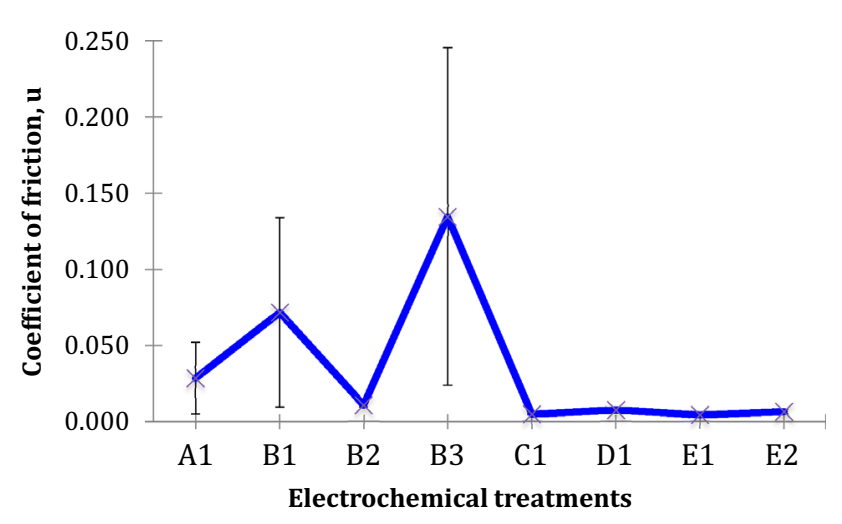

Fig. 8 Coefficient of friction (COF) $(\mu)$ for different electrochemical treatments with their respective variability values. A1 (control), B1 $(+0.7 \mathrm{~V}, 0 \mathrm{~g} / \mathrm{L} \mathrm{BCS}), \mathrm{B} 2(+0.7 \mathrm{~V}, 15 \mathrm{~g} / \mathrm{L} \mathrm{BCS}), \mathrm{B} 3(+0.7 \mathrm{~V}, 30 \mathrm{~g} / \mathrm{L}$ BCS $),$ C1 $(+0.8 \mathrm{~V}, 30 \mathrm{~g} / \mathrm{L}$ BCS $), \mathrm{D} 1(+0.6 \mathrm{~V}, 30 \mathrm{~g} / \mathrm{L} \mathrm{BCS}), \mathrm{E} 1$ $(-0.4 \mathrm{~V}, 0 \mathrm{~g} / \mathrm{L})$, and E2 $(-0.4 \mathrm{~V}, 30 \mathrm{~g} / \mathrm{L})$

molybdenum, carbon, and nitrogen were quantified. Table 5 represents the EDS scans of CoCrMo alloy samples' surface with different electrochemical treatments. Nitrogen was detected using EDS and it is a good indicator of organic material present on the alloy surfaces. Additionally the carbon peak increased significantly on the samples that contained BCS in their electrolyte. There was a consistent decrease in the amount of cobalt content as the potential changed rom cathodic to anodic toward the transpassive potentials.

\section{Discussion}

This study evaluated surface properties of the electrochemically treated CoCrMo alloy, more specifically the stability of the film formation, as a function of protein content and transpassive potentials. Evaluation of nanomechanical properties and morphological mapping of CoCrMo surfaces subjected to different electrochemical treatments illustrated the effect of distribution and protein accumulation in the presence of anodic and cathodic potentials.

\subsection{General Aspects of the Role of Protein and Corrosion Damage at Transpassive Potential on the Treated Surface}

Samples treated with anodic potentials displayed localized corrosion regardless the concentration of $\mathrm{BCS}$ in the electrolyte as observed from the EDS analysis. Most of the basins formed in the matrix were confined to what it appears to be carbide clusters, grain boundaries, and/or surface defects such as polishing marks. Two possible mechanisms can be accounted for these features: (1) the surrounding areas of carbides are open to localize attack by leaching chromium away from the matrix [36] when exposed to these transpassive anodic potentials. (2) Proteins interact with molybdenum and chromium ions creating chemical bonds, thus depleting the matrix from these corrosion-resistant elements [28]. Furthermore, the accumulation of protein on the surface depletes the surroundings from oxygen compromising the stability of the passive film causing localized corrosion [38].

\subsection{Surface Properties of the Treated Surface at Transpassive Potential with Varying Protein Content}

Sample B1 $(+0.7 \mathrm{~V}, 0 \mathrm{~g} / \mathrm{L}$ BCS $)$ had the highest coefficient of friction (COF) among all the other treatments regardless of their electrolyte concentration. This treatment triggered nucleation and growth of grain boundaries. The COF for B1 oscillated significantly with values ranging from $9 \times 10^{-3}$ to $1.34 \times 10^{-1}$. This oscillation in $\mathrm{COF}$ was due to the small scan area sizes $(1 \mu \mathrm{m})$ that had to be used during COF experiments. The fluctuations on values could be attributed to the cantilever being in contact with only one type of surface most of the time through each scanned section. So either asperities (carbide areas) or smooth areas, which were still covered with undamaged oxide layer, generated high or low COF, respectively. The roughness value of B1 was the lowest among all the anodic treatments despite not having any protein in the electrolyte. This treatment could still have parts of the oxide layer that
Table 5 Representative chemical analysis from electron-dispersive X-ray spectroscopy (EDS)

\begin{tabular}{llrrrr}
\hline Sample (voltage/electrolyte concentration) & \multicolumn{2}{l}{ Weight percentage $\%$} & & \\
\cline { 2 - 6 } & C & N & Mo & Co & Cr \\
\hline E1 (-0.4 V, 0 g/L BCS) & 0.13 & 0.01 & 10.50 & 61.09 & 28.27 \\
E2 (-0.4 V, 30 g/L BCS) & 2.78 & 1.42 & 9.10 & 61.93 & 24.78 \\
B1 (+0.7 V, 0 g/L BCS) & 1.34 & 0.10 & 11.71 & 59.00 & 27.86 \\
B2 (+0.7 V, 15 g/L BCS) & 3.04 & 1.51 & 14.90 & 54.21 & 26.35 \\
B3 (+0.7 V, 30 g/L BCS) & 2.31 & 1.70 & 14.32 & 54.70 & 26.97 \\
D1 (+0.6 V, 30 g/L BCS) & 7.20 & 1.99 & 16.30 & 42.83 & 31.69 \\
C1 (+0.8 V, 30 g/L BCS) & 34.67 & 7.61 & 13.99 & 21.23 & 22.51 \\
\hline
\end{tabular}


are contributing to the lower roughness values. Nevertheless, B1 roughness was still three times higher than E1 $(-0.4,0 \mathrm{~g} / \mathrm{L} \mathrm{BCS})$, which surface was covered with an intact oxide layer. Similar to sample B2 was sample B3 $(+0.7 \mathrm{~V}, 30 \mathrm{~g} / \mathrm{L})$, which displayed lower COF due to the presence of the protein that acted as a lubricant on certain areas. The COF values for these two treatments decreased by 85 and $67 \%$, respectively, when compared to the control without any treatment.

Sample B3 did not yield denser or more homogeneous surface coverage, despite having double the protein concentration in the electrolyte but same anodic potential of $+0.7 \mathrm{~V}$ as B2. From EDS analysis, high concentrations of nitrogen and increased carbon content on the surface of this sample were observed indicating protein deposition and the formation of a proteinaceous layer. When proteins form chemical bonds with the metal ions around the carbide boundaries or grain boundaries, protein deposition takes place [28], restricting the diffusion of oxygen into the basin structures [41]. As oxygen is depleted, release of metal ions from the surface create a net positive charge inside these cavities, ensuing in an influx of chloride ions, present in the electrolyte, to maintain the charge balance [21]. Sample B3 had not only the largest COF but also the major variability among all samples as evident from the scatter bars. This is due to experimental limitations while performing lateral force microscopy (LFM). Only small areas of 1 um were investigated to determine the $\mathrm{COF}$ in order to reduce the error introduced by the high wear and deformation that probe tips undergo while on raster mode [31].

The protein agglomerates acted as lubricant patches [27] in some areas yielding COF values as low as 0.025 . The regular debris that formed due to the electrochemical treatment could further increase the COFs on the carbide areas explaining some of the high $\mathrm{COF}$ values observed for B3.

\subsection{Surface Properties of the Treated Surface at Transpassive Potential $(+0.6$ and +0.8$)$ at $30 \mathrm{~g} / \mathrm{L}$ Protein Content}

As the potential was increased from +0.6 to $+0.8 \mathrm{~V}$, while keeping constant the electrolyte concentration $(30 \mathrm{~g} / \mathrm{L}$ $\mathrm{BCS})$, the protein coverage increased due to the presence of more free positive metal ions that could be bound to the negatively charged proteins. Sample C1 $(+0.8 \mathrm{~V}, 30 \mathrm{~g} / \mathrm{L}$ BCS) achieved the largest basin diameters among all the samples with values up to $6.62 \mu \mathrm{m}$ that possibly resulted from a mixture of carbides and proteinaceous materials. This suggests that protein in the electrolyte solution plays a role in accelerating the corrosion process when combined with a high transpassive potential as indicated by the increase in nitrogen and the decrease in cobalt content on these samples from the EDS analysis. The suggested mechanism of corrosion is through protein and metal ion interaction in which proteins take up chromium and molybdenum away from the matrix depriving it of these highly corrosion-resistant elements accelerating the corrosion process $[6,36,39]$. These two types of treatments at +0.6 and $+0.8 \mathrm{~V}$ may lead to metal dissolution causing adverse physiological effects as previously described. This metal dissolution was observed from EDS analysis by observing the decrease on cobalt content from the surface. The roughness values in sample $\mathrm{C} 1$ are comparable with B3, but no significant correlation could be established between roughness and their corresponding COF. Although $+0.8 \mathrm{~V}$ potential outcomes in a proteinaceous layer, significant grain and carbide boundary corrosion resulted of the increased potential are not a viable potential treatment.

Sample D1 $(+0.6 \mathrm{~V}, 30 \mathrm{~g} / \mathrm{L}$ BCS $)$ had protein aggregates that were more confined onto areas that have been corroded such as the edges of carbides and grain boundaries. From the values recorded for protein film thickness, protein adsorption was not restricted to a monolayer since the protein concentration for all the treatments exceeded $10 \mathrm{~g} / \mathrm{L} \mathrm{BCS}$, which is the upper limit for monolayer deposition [16-18, 20]. The lower COF values for both samples $\mathrm{C} 1$ and D1 when compared with A1 (control) confirmed the lubrication effect of BCS on those areas. Both $\mathrm{C} 1$ and D1 COFs were slightly higher than sample E1, which surface was treated with $-0.4 \mathrm{~V}$ without protein in the electrolyte. This indicates that the corrosion caused by the transpassive potential and the presence of protein influenced their respective COFs.

\subsection{Surface Properties of the Treated Surface at Passive Potential with and Without Protein Content}

Sample E1 ( $-0.4 \mathrm{~V}, 0 \mathrm{~g} / \mathrm{L}$ BCS) roughness and COF results corroborates the fact that the passive oxide layer formed with this negative potential imparts lubrication characteristics to the substrate and will provide stability to the alloy by resisting the thermodynamic tendency to rapidly dissolve $[28,52]$.

The protein layer on sample E2 $(-0.4 \mathrm{~V}, 30 \mathrm{~g} / \mathrm{L} \mathrm{BCS})$ had a more even distribution of protein than any other treatment that contained BCS in its electrolyte. There was no agglomeration in this particular sample, except there were some areas without coverage. Also this sample displayed a COF above the value measured for E1 $(-0.4 \mathrm{~V}$, $0 \mathrm{~g} / \mathrm{L}$ ). This is probably due to damage of the oxide layer caused by the presence of BCS on some areas. The average $\mathrm{COF}$ for $\mathrm{E} 1$ ranged from $8 \times 10^{-3}$ to $5.2 \times 10^{-3}$, where the higher values could be related to the initial breakdown of the oxide layer. The initial dissolution of the oxide layer 
was observed by the decrease in chromium from the EDS analysis, which makes most of the oxide layer of this alloy as $\mathrm{Cr}_{2} \mathrm{O}_{3}$. This small degree of corrosion was probably initiated by the BCS layer on the surface of the sample, which led to deactivation, crystallization [9] or dissolution of the thin oxide layer through ion interactions and protein degradation. The process of adsorption of proteins onto surfaces of the metal could have also limited the diffusion of oxygen to certain areas on the surface creating oxygendeficient regions and breakdown of the passive layer, thus initiating corrosion at a small scale. Further studies are required on the specific corrosion kinetics and to determine the beneficial effect of the electrochemically generated tribolayer.

\subsection{The Role of Protein Content on Surface Damage and Friction Coefficient Evolution During the Film Formation: Possible Mechanisms}

The protein aggregation observed on all the transpassive potentials $(+0.6,+0.7$, and $+0.8 \mathrm{~V})$ allowed pre-eminent areas of corrosion, which would lead to metal dissolution. From Fig. 8, it can be acknowledged that there was a benefit to having a BCS layer, which reduced the COF in most cases. The smooth surface from the oxide layer in sample E1 acted as a protective barrier, thus significantly reducing all other forms of corrosion. However, passive films could easily be removed under tribological events exposing the bulk material, which has low lubrication properties.

The $-0.4 \mathrm{~V}$ sample in $30 \mathrm{~g} / \mathrm{L}$ protein content did not display any grain boundary corrosion on the surface after treatment. Making this electrochemical treatment, the most optimal out of all the others used in this study. However, aggregation of proteins was observed for all the anodic electrochemical treatments with BCS in their electrolyte; around the carbide, grain boundaries, and defects. This aggregation may start occurring even at the beginning of film deposition when proteins bind to the metal ions forming a protein-metal complex. This process increases the removal of ions during the electrochemical treatment consequently depleting the matrix even more from corrosion protective elements such as chromium and molybdenum. Remarkably, the coefficients of friction decreased only where the presence of the simulated tribolayer was observed.

A relationship between roughness values and COF could not be established in this study. Previous studies using AFM and proteins have not found a correlation either between surface roughness and COF [35]. This holds true whenever there is a strong influence of localized variations in the material properties as seen in the inhomogeneous distribution of surfaces asperities. A correlation could possibly exist if larger surface areas were studied.

These results corroborate studies previously conducted by Mathew [29] where tribocorrosion wear testing showed how proteins affect materials degradation and dissolution. It is also well known that most proteins in the physiological fluids absorb on charged surfaces due to electrostatic attraction between the surface and opposite-charged functional groups along polypeptide chain of protein molecules $[20,27]$. Consequently, protein agglomerates were predominately seen at grain and/or carbide boundaries, which are either enriched or depleted of one of the alloying elements, initiating intergranular corrosion $[8,47]$. Although carbides themselves are quite corrosion resistant, the regions around carbides can be depleted of chromium. These areas may not have enough chromium to resist oxidation $[11,36]$. Moreover, this corrosion and proteinion interaction gives rise to the proteinaceous layer that has been observed on hip implant retrievals [29]. Also, it is believed that proteins adsorb to the metal surface creating a solid lubricating surface layer [40]. This observation was confirmed in this study by the lower COF obtained when the substrates were treated with anodic potentials and an electrolyte containing BCS. The presence of proteinaceous material on the CoCrMo surface could improve surface separation between the MoM bearing surfaces and thus minimizes wear-corrosion rates.

\subsection{Clinical Significance of the Study}

This study deals with the nanoscale surface morphology and characterization of the electrochemical treated film, which is simulating the tribolayer observed on the retrieved implant surfaces. The clinical relevance of this study is that the simulated tribolayer could provide boundary lubrication within the joint and reduce friction as observed from the low COF. Although this tribolayer formation on CoCrMo alloy spreads throughout the surface, it is not homogeneous it could cause further dissolution of the metal in vivo at localized areas [52]. Additionally thirdbody particles generated from the articulating surfaces of MoM joints can cause deep grooves where hard asperities (the carbides) make contact with their opposite surface [43], which could also lead to the release of more metal ions and wear debris. Conversely spreading of the protein in the presence of frictional motion could smooth the surface and add protection to the rest of the areas that were not covered initially by protein during the electrochemical treatments. However, the nano-crystal layer, which is initially mechanically mixed with the carbonaceous material $[50,51]$ could be destroyed by frictional forces. It is worthwhile to state that the reported study only addresses 
the nano-mechanical properties of the artificially generated tribolayer through electrochemical treatment. Hence, further studies are required to evaluate the effectiveness of the electrochemically generated tribolayer for the biomedical implant application and how micro-/nanoscale wear can impact the performance of the tribolayer. We are considering to test this simulated tribolayers in hip simulator, where the spreading of the protein during in vivo cyclic mechanical loading is tested (tribocorrosion simulations). In addition, simulation of cyclic forces that deliver homogeneous distributions of the protein will help in the formation of well-developed tribolayer on the articulating implant surfaces. Further research also required to understand the specific corrosion kinetics of the treated surfaces in in vivo conditions and if there is subsequent metal ion release or hindrance to the surrounding environment.

\section{Conclusions}

The surfaces properties of the treated surfaces are largely influenced by the protein content and exposed potentials. The treated surfaces at transpassive potential displayed higher level of protein deposition as the anodic potentials increased but at the same time more inhomogeneity on its distribution. For samples subjected to transpassive potentials, although the presence of tribolayer was evident, a clear pattern on protein deposition and distribution could not be identified. Remarkably, the coefficients of friction decreased only where the presence of tribolayer is increased for all the electrochemical treatments used. A relationship between roughness values and COF could not be established in this study. Mostly due to the small areas that were selected for the COF studies. Future studies are required to test the effect of proteinaceous layer during a simulated micro-abrasion-corrosion (tribocorrosion) process to evaluate if the tribolayer formed could impede the charge transfer hence reducing metal dissolution. These investigations would aid in the developing of an innovative surface treatment for implant surfaces that will not cause allergic reactions and cytotoxicity to the surrounded tissues in a patient due to the release of metal ions, which is a major clinical concern in the orthopedic community.

Acknowledgments The authors would like to thank the University of Texas at Dallas for providing resources for this research through startup funds (D. Rodrigues). We also thank The Vascular Mechanobiology Lab (University of Texas at Dallas) for providing access to the AFM facilities and the fellowship from Coordenacao de Aperfeicoamento de Pessoal de Nivel Superior (CAPES) (IMG). The authors from Rush University Medical Center would like to recognize and thank funding from the NSF (FDN 1160951) and intellectual contributions and support from Dr. Wimmer (RUMC) and Dr. Pourzal (RUMC) and Dr. E. Martin (NU). We would also like to thank The College of Dentistry at The University of Illinois at Chicago,
Chicago, IL and The Department of Orthopedics, Rush University Medical Center, Chicago, IL for providing both funding and lab facilities.

\section{References}

1. Burbano M, Russell R, Huo M, Welch R, Roy D, Rodrigues DC (2014) Surface characterization of retrieved metal-on-metal total hip implants from patients with adverse reaction to metal debris. Materials 7(3):1866-1879

2. Catelas I, Wimmer MA (2011) New insights into wear and biological effects of metal-on-metal bearings. J Bone Joint Surg Am 93(Supplement 2):76-83

3. Celis JP (2006) Pierre Ponthiaux Ecole Centrale Paris, Lab LGPM, F-92295 Châtenay-Malabry, France Corresponding author. E-mail address: ponthiaux@ lgpm. ecp. fr. Wear 261: 937-938

4. Charitidis CA (2010) Nanomechanical and nanotribological properties of carbon-based thin films: a review. Int J Refract Metal Hard Mater 28(1):51-70

5. Clayton RA, Beggs I, Salter DM, Grant MH, Patton JT, Porter DE (2008) Inflammatory pseudotumor associated with femoral nerve palsy following metal-on-metal resurfacing of the hip. JBJS Case Connector 9:1988-1993

6. Contu F, Elsener B, Böhni H (2003) Electrochemical behavior of CoCrMo alloy in the active state in acidic and alkaline buffered solutions. J Electrochem Soc 150(9):B419-B424

7. Delaunay C, Petit I, Learmonth ID, Oger P, Vendittoli PA (2010) Metal-on-metal bearings total hip arthroplasty: the cobalt and chromium ions release concern. Orthop Traumatol Surg Res 96(8):894-904

8. Disegi JA, Eschbach L (2000) Stainless steel in bone surgery. Injury 31(suppl 4):2-6

9. Effah EAB, Bianco PD, Ducheyne P (1995) Crystal structure of the surface oxide layer on titanium and its changes arising from immersion. J Biomed Mater Res 29(1):73-80

10. Fischer A, Weiss S, Wimmer MA (2012) The tribological difference between biomedical steels and CoCrMo-alloys. J Mech Behav Biomed Mater 9:50-62

11. Fontana MG, Greene ND (1978) Chapter 3: eight forms of corrosion in corrosion engineering. McGraw-Hill, New York, pp 39-85

12. Gallo J, Coer A, Jämsen E, Gibon E, Thyssen JP, Pajarinen J, Mackiewicz Z (2012) Aseptic loosening of total hip arthroplasty as a result of local failure of tissue homeostasis. INTECH Open Access Publisher, Rijeka

13. Gilbert JL, Bai Z, Bearinger J, Megremis S (2004) The dynamics of oxide films on metallic biomaterials. In: Proceedings of materials and processes from medical devices conference. ASM International, Anaheim, pp 139-143

14. Greiner C, Felts JR, Dai Z, King WP, Carpick RW (2010) Local nanoscale heating modulates single-asperity friction. Nano Lett 10(11):4640-4645

15. Hailer NP, Bengtsson M, Lundberg C, Milbrink J (2014) High metal ion levels after use of the $\mathrm{ASR}^{\mathrm{TM}}$ device correlate with development of pseudotumors and $\mathrm{T}$ cell activation. Clin Orthop Relat Res 472(3):953-961

16. Hodgson AWE, Kurz S, Virtanen S, Fervel V, Olsson CO, Mischler S (2004) Passive and transpassive behaviour of CoCrMo in simulated biological solutions. Electrochim Acta 49(13): 2167-2178

17. Horowitz SM, Luchetti WT, Gonzales JB, Ritchie CK (1998) The effect of cobalt chromium upon macrophages. J Biomed Mater Res 41(3):468-473 ISSN 0021-9304 
18. Igual Muñoz A, Mischler S (2007) Interactive effects of albumin and phosphates ions on the corrosion of CoCrMo implant alloy. J Electrochem Soc 154(10):C562-C570

19. Hu J, Xiao XD, Ogletree DF, Salmeron M (1995) Atomic-scale friction and wear of mica. Surf Sci 327:358-370

20. Jeyachandran YL, Mielczarski E, Rai B, Mielczarski JA (2009) Quantitative and qualitative evaluation of adsorption/desorption of bovine serum albumin on hydrophilic and hydrophobic surfaces. Langmuir 25(19):11614-11620

21. Kauser F (2007) Corrosion of CoCrMo alloys for biomedical applications (Doctoral dissertation, University of Birmingham, Department of Metallurgy and Materials, School of Engineering)

22. Kocijan A, Milošev I, Pihlar B (2004) Cobalt-based alloys for orthopaedic applications studied by electrochemical and XPS analysis. J Mater Sci Mater Med 15(6):643-650

23. Kulik AJ, Lekka M, Lee K, Pyka-Fościak G, Nowak W (2015) Probing fibronectin-antibody interactions using AFM force spectroscopy and lateral force microscopy. Beilstein J Nanotechnol 6(1):1164-1175

24. Landolt D (2006) Electrochemical and materials aspects of tribocorrosion systems. J Phys D Appl Phys 39(15):3121

25. Lee C, Li Q, Kalb W, Liu XZ, Berger H, Carpick RW, Hone J (2010) Frictional characteristics of atomically thin sheets. Science 328(5974):76-80

26. Liao Y, Pourzal R, Wimmer MA, Jacobs JJ, Fischer A, Marks LD (2011) Graphitic tribological layers in metal-on-metal hip replacements. Science 334(6063):1687-1690

27. Malmsten M (1998) Formation of absorbed protein layers. J Colloid Interface Sci 207:186-199

28. Martin EJ, Pourzal R, Mathew MT, Shull KR (2013) Dominant role of molybdenum in the electrochemical deposition of biological macromolecules on metallic surfaces. Langmuir 29(15):4813-4822

29. Mathew MT, Jacobs JJ, Wimmer MA (2012) Wear-corrosion synergism in a CoCrMo hip bearing alloy is influenced by proteins. Clin Orthop Relat Res 470(11):3109-3117

30. Mathew MT, Nagelli C, Pourzal R, Fischer A, Laurent MP, Jacobs JJ, Wimmer MA (2014) Tribolayer formation in a metalon-metal (MoM) hip joint: an electrochemical investigation. J Mech Behav Biomed Mater 29:199-212

31. Maw W, Stevens F, Langford SC, Dickinson JT (2002) Single asperity tribochemical wear of silicon nitride studied by atomic force microscopy. J Appl Phys 92(9):5103-5109

32. Milošev I (2012) The effect of biomolecules on the behaviour of CoCrMo alloy in various simulated physiological solutions. Electrochim Acta 78:259-273

33. Milošev I, Strehblow HH (2003) The composition of the surface passive film formed on CoCrMo alloy in simulated physiological solution. Electrochim Acta 48(19):2767-2774

34. Mischler S (2008) Triboelectrochemical techniques and interpretation methods in tribocorrosion: a comparative evaluation. Tribol Int 41(7):573-583

35. Park S, Costa KD, Ateshian GA (2004) Microscale frictional response of bovine articular cartilage from atomic force microscopy. J Biomech 37(11):1679-1687
36. Placko HE, Brown SA, Payer JH (1998) Effects of microstructure on the corrosion behavior of $\mathrm{CoCr}$ porous coatings on orthopedic implants. J Biomed Mater Res 39(2):292-299

37. Pound BG (2010) Electrochemical behavior of cobalt-chromium alloys in a simulated physiological solution. J Biomed Mater Res Part A 94(1):93-102

38. Ratner BD, Hoffman AS, Schoen FJ, Lemons JE (2004) Biomaterials science: an introduction to materials in medicine. Elsevier Academic Press, San Diego

39. Sargeant A, Goswami T (2007) Hip implants-paper VI-ion concentrations. Mater Des 28(1):155-171

40. Scholes SC, Unsworth A (2006) The effects of proteins on the friction and lubrication of artificial joints. Proc Inst Mech Eng $\mathrm{H}$ 220(6):687-693

41. Seah KHW, Thampuran R, Teoh SH (1998) The influence of pore morphology on corrosion. Corr Sci 40:547-556

42. Shimmin A, Beaulé PE, Campbell P (2008) Metal-on-metal hip resurfacing arthroplasty. J Bone Joint Surg 90(3):637-654

43. Sinnett-Jones PE, Wharton JA, Wood RJK (2005) Micro-abrasion-corrosion of a CoCrMo alloy in simulated artificial hip joint environments. Wear 259(7):898-909

44. Sundararajan S, Bhushan B (2000) Topography-induced contributions to friction forces measured using an atomic force/friction force microscope. J Appl Phys 88:4825-4831

45. Svensson O, Mathiesen EB, Reinholt FP, Blomgren G (1988) Formation of a fulminant soft-tissue pseudotumor after uncemented hip arthroplasty. J Bone Joint Surg Am 70:1238-1242

46. Vidal CV, Muñoz AI (2011) Electrochemical aspects in biomedical alloy characterization: electrochemical impedance spectrosopy. INTECH Open Access Publisher, Rijeka

47. Walczak J, Shahgaldi F, Heatley F (1998) In vivo corrosion of 316L stainless-steel hip implants: morphology and elemental compositions of corrosion products. Biomaterials 19:229-237

48. Williams RL, BrownSA Merritt K (1988) Electrochemical studies on the influence of proteins on the corrosion of implant alloys. Biomaterials 9(2):181-186

49. Wimmer MA, Sprecher C, Hauert R, Täger G, Fischer A (2003) Tribochemical reaction on metal-on-metal hip joint bearings: a comparison between in vitro and in vivo results. Wear 255(7):1007-1014

50. Wimmer MA, Fischer A, Büscher R, Pourzal Sprecher C, Hauert $\mathrm{R}$, Jacobs JJ (2010) Wear mechanisms in metal-on-metal bearings: the importance of tribochemical reaction layers. J Orthop Res 28(4):436-443

51. Wimmer M, Mathew M, Laurent M, Nagelli C, Liao Y, Marks L, Pourzal R, Fischer A, Jacobs J (2013) Tribochemical reactions in metal-on-metal hip joints influence wear and corrosion. In: Metal-on-metal total hip replacement devices. ASTM International

52. Yan Y, Neville A, Dowson D (2007) Biotribocorrosion of CoCrMo orthopaedic implant materials - assessing the formation and effect of the biofilm. Tribol Int 40(10):1492-1499 